\title{
INFLUENCING MATHEMATICS STUDENTS' ACADEMIC SUCCESS THROUGH ONLINE INTERVENTION: A CASE STUDY
}

\author{
J. P. Adamiak* \\ e-mail: jaradamiak@gmail.com
}

\section{R. D. Sauls*}

e-mail: raesau@live.com

*Western Cape Tuition and Facilitation of Learning

University of South Africa Western Cape Regional Office

Cape Town, South Africa

\section{ABSTRACT}

Open distance learning (ODL), by the definition, subscribes to the limited direct engagement of the students with the learning institution. The University of South Africa (UNISA), Western Cape, has placed key emphasis on providing an array of electronic support platforms to assist students with their needs in quantitative literacy skills. Consequently, as a part of this additional learning support, an online environment was designed in which the students, enrolled for various mathematics modules, were able to access an array of educational resources. Findings from similar studies suggest, that the utilisation of employment of additional learning support could show a positive effect on students' academic achievement in distance learning. Therefore, a quasiexperimental research study was conducted to investigate this supposition by comparing the assessment outcomes among various student groups subjected to the additional learning support interventions. It has been found that online intervention might affect the success rate of the students, however, not necessarily in a simple or in the anticipated way.

Keywords: ODL, additional learning support, online, blended, face-to-face, student's success, OER

\section{INTRODUCTION}

When distance learning was in its infancy, the instructional media, which can be defined as being the physical means by which instruction was presented to learners (Holden and Westfall 2010), were severely limited. Thus, the acquisition of knowledge was accomplished by assimilating handwritten information. The first occurrences of this phenomenon were recorded in St. Paul's letters (Jarvis 2006) and in the messages by Genghis Khan (Baggaley 2012). Subsequently, advances in technology and their applications, from the printing press, through to the postal service, radio and television and to the internet and cellular networks, allowed students to diversify and amalgamate the instructional media in order to support their personal 
choice of technology and learning modality.

At Unisa, a major ODL institution in South Africa and worldwide, first-year undergraduate students are expected to use prescribed books and study guides as a baseline for their daily studies. The main communication channel for the curriculum description, study material, assignments and exam preparation comprises tutorial letters and static web pages. However, this process, does not guarantee that the student is going to be successful in his or her studies, so the university is actively involved in researching and providing various means of additional support. Hoping to improve the level of success, the learning experience at Unisa was enhanced by the employment of face-to-face tutorial support for selected modules, etutoring, consultations, counselling and student advice services. Additionally, the dedicated online facilities were recently introduced as an alternative to or to complement the other modes of knowledge acquisition.

There is no universal agreement on the precise definition of online learning (Moore, Dickson-Deane and Galyen 2011). In our context, with regard to the provision of online facilities, it is understood that, in the framework of additional support, the students are given access to the internet gateway where links to various Open Educational Resources (OERs) are available. Nonetheless, there were, strictly speaking, no online classes or courses, but the tutors or facilitators on the campus would encourage the students to register and use the Quantitative Literacy (QL) portal at their discretion.

In this research, we grouped the ODL students according to their mode of accessing the additional support.

- $\quad$ The face-to-face (F2F) group comprised students attending tutorials, but who have no access to the QL portal.

- The online group incorporated students who have access to the QL portal, but who do not attend tutorials.

- $\quad$ The blended group constituted students who attended tutorials and accessed the QL portal.

Our purpose was to examine the relationship between the students' academic success and the mode of additional support delivery. In particular, the focus was to investigate whether online delivered Open Education Resources (OERs) complemented the acquisition of mathematical competence in distance learning. Thus, our research question states: 'Is there a positive difference in the assignment and exam results of students participating in online, face-to-face and blended additional support services versus the general population of students?' We also asked: 'Is the online mode preferred to the F2F and blended modes of learning when the 
summative assessment outcome forms the dominant deciding factor?'

\section{REVIEW OF THE LITERATURE}

Although the success of the students is a major concern for any higher education institution throughout the world, the educators are not always in agreement as to what exactly it means for students of those institutions to be successful. The success is often considered in terms of a number of desirable outcomes, among them, student retention, educational attainment, student advancement, holistic development and academic achievement (Cuseo 2007). A South African framework was developed at Unisa to understand, predict and enhance student success in ODL (Subotzky and Prinsloo 2011), where the notion of success is broadly defined to include retention, persistence, course success and graduation as well as student satisfaction and effective graduate attributes.

When narrowed down to a single course or module, one might define success in terms of the pass rates (Ashby, Sadera and McNary 2011) and the various assessment results, which belong to the academic achievement category.

Open Educational Resources (OERs) can be defined as educational materials that use a Creative Commons license or that is in the public domain and are free of copyright restrictions (Wiley, Bliss and McEwen 2014). Students and faculty members view OERs in a positive light, however, it is not clear whether these resources have had any major impact on student learning (Hilton et al. 2013). Nonetheless, there is some scepticism in academia in fully embracing OERs, as they might not enhance an academic career, but it seems that this issue can be mitigated via a provision of proper motivators (Browne et al. 2010). In general, a goal that OERs hopes to achieve is to establish a creative space, where the university staff and students can meet and develop resources within an interactive curriculum (Browne and Newcombe 2009). In the South African context, OERs might provide economically viable means for raising the educational standards.

Also, the study was conducted in the mathematical field and a number of suggestions for policy-makers, practitioners and researchers were offered (Sapire and Reed 2011). To add more of a local flavour, in 2007 there was a meeting convened in Cape Town that gave rise to 'The Cape Town Open Education Declaration' (Declaration CTOE 2007), signed by hundreds of learners, educators, trainers, schools, colleges, universities and other educational institutions and societies from around the world. In particular, this declaration provides a vision expressed in the form of strategies towards collaboration on OERs that would make it possible to redirect funds from expensive textbooks towards inexpensive learning resources. In summary, as succinctly put by Butcher (2015), OER encapsulates a potential vision for educational systems 
globally, wherein individual educators, and then increasingly entire departments and institutions, can come together in common online spaces - which, like most successful internet phenomena, are not 'owned' by anyone, institutional or corporate - to start sharing the materials they have produced in an effort, ultimately, to ensure that all the material that students need to be able to complete their studies, can be successfully accessed - legally - without any costs of licensing.

OERs can be combined into an educational entity according to the learning objects (LOs) framework. Originally, the term LO was introduced by the IEEE Learning Technology Standards Committee as any entity, digital or non-digital, that may be used for learning, education or training (Learning Technology Standards Committee 2002). Subsequently, the definition evolved to 'a collection of content items, practice items, and assessment items that are combined based on a single objective' (Barritt, Lewis and Wieseler 1999). Such an approach to technologically-enhanced education is considered to be promising and popular, as it supports reusability in different contexts, leading to a minimisation of production cost (Chawla, Gupta and Singla 2012). Recently, LO development has been inclined to move towards achieving closer compliance with Object-oriented Programming principles (Raghuveer and Tripathy 2012), one of the most successful paradigms in the software engineering discipline. Consequently, it is required of LOs to fulfil the following three requirements (Polsani 2006):

- $\quad$ accessibility: the LO should be tagged with metadata so that it can be stored and referenced in a database

- $\quad$ reusability: once created, a LO should function in different instructional contexts

- $\quad$ interoperability: the LO should be independent of both the delivery media and knowledge management systems

These guidelines were created in the spirit of 'write-once, run-everywhere' philosophy, similar to the paradigm of the Java programming language (Tyma 1998). Hence, in the light of the strong principles applied to LO construction, it seems to be prudent to follow this framework when designing the educational portal for ODL students.

In research conducted in the United Kingdom, it was found that, unless the universities provide appropriate forms of learning support for mathematics and statistics students, it is inevitable that there will be an adverse impact on their students' satisfaction, retention, achievement and employability (Tolley and MacKenzie 2015). Also, similar issues were noticed in the United States, as this country experiences an urgent need to develop mathematical literacy (Jaafar, Toce and Polnariev 2016). In South Africa, it was found that the learning 
support services assisted in meeting learners' academic, social and emotional needs by addressing barriers to learning, creating conducive learning environments, enhancing learners' self-esteem and improving learners' academic performance in Western Cape schools (Bojuwoye et al. 2014). An interesting and highly successful type of learning support programme, is the supplemental instruction. The idea behind this type of support is that the learning of a subject is enhanced by an exchange of thoughts and ideas among students, where the discussion is guided by advanced students, trained to be supplemental instruction leaders (Malm, Bryngfors and Morner 2011). However, the success rate of supplemental instruction in the area of mathematics, ranged from being inconclusive (Phelps and Evans 2006) to successful (Dias, Cunningham and Porte 2016). As students in ODL are prone to lower rates of retention and completion than campus-based students, there is growing interest around distance-specific learning support (Brown et al. 2013).

The learning modes that are in the orbit of our interest comprise three environments: online, face-to-face and blended - where the latter has been defined as a combination of the former two. Thus, we might define these modes as follows (Allen, Seaman and Garrett 2007):

- $\quad$ face-to-face (traditional): no online technology used; content is delivered in writing or orally

- online: most or all of the content is delivered online; typically have no face-to-face meetings

- $\quad$ blended: blends online and face-to-face delivery; a substantial proportion of the content is delivered online, typically uses online discussions, and typically participates in some faceto-face meetings

There is no universal consensus on the position of any of the learning modes (Allen and Seaman 2011) when it comes to the effectiveness of instruction. However, some researchers in this field reported a slight advantage for the face-to-face mode over the online option (Sharma, Bryant and Murphy 2013) and the opposite of that in Ashby et al. (2011). An absence of any meaningful difference had also been observed (Smith 2013). Also, a more complicated relationship between these modes can occur, for example, student performance was reported as a decreasing function of learning abstraction in an online teaching environment versus a traditional face-to-face approach (Lu and Lemonde 2013; Ross and Bell 2007).

The intersection of the findings in the abovementioned research, leads to our research problem. In general, there is an abundance of papers in the areas of holistic student success, OERs construction and dissemination, online versus face-to-face course design and additional 
support in ODL. However, to our knowledge, there is not much available research that investigates OER-based online support facilities, as a companion to the ODL degree programme and its influence on students' academic success in the context of a single course or module. This article attempts to narrow the gap by launching a quasi-experimental probe of this issue at the Unisa Western Cape Regional Office: Learning Facilities.

\section{METHODOLOGY}

The additional support programme, has been operational since 2012 in the form of face-to-face tutorials, workshops and consultations. In the second half of 2014, the construction of the QL portal was initiated as an offering that facilitated learning support in the online mode. The development took approximately a year and the final version of the portal was stabilised at the end of the first semester 2015. Background data was collected during the first semester of 2015 (we will report on it further, elsewhere in this article) despite the fact that the online facility was not performing at full capacity during this semester and the research phase took place during the second semester of 2015.

Recruitment for the additional online support was conducted by means of institutional email services and students' alternative e-mail, SMS facility and direct telephone calls. The QL portal comprised four major components:

- $\quad$ a website built on the Google technology

- $\quad$ pages with links to OERs that were grouped into LOs

- $\quad$ roadmaps relating study programmes and relevant LOs

- $\quad$ menu, search facility and interlinkage of LOs facilitating the site traversals

The website has been built with special attention paid to the best design principles, as described in Raward (2001). We were aware that OL is going to be accessed by end-users who have severely limited bandwidth at their disposal (Oyedemi 2012) as well as end-users whose primary web-browsing technology is a mobile phone. This is why we did not incorporate graphic images, icons or banners to the portal architecture and maintained the component sizes to the necessary minimum.

The portal used the Google Site administration features that helped with providing the control regarding accessibility of the website to the students participating in the project. In order to affirm that the portal was actively visited by the enrolled students, we employed the Google Analytics facility, which provides a vast array of visitor statistics and detailed records of the site traversals. Moreover, the site developers and administrators were asked to use nonstandard 
browsers during the performance of their tasks, to ensure that the data is not contaminated by the maintenance traffic. During the first semester, the portal acquired 468 sessions with 1882 page views. Then, during the second semester, the session number increased to 474 and the page views reached 1857.

The site visiting patterns have shown, as outlined in figure 1 and figure 2, that the attendance peaks were concentrated around significant events during the semesters, for example, induction sessions, mass mail announcements, workshops, assignment submission dates and the exams. The threat of student attrition did not materialise - as found in, for example, Clow (2013) - despite the fact that participation in the additional learning support programme was not compulsory. On the contrary, the linear model fitted to the number of sessions and page views per day indicated the attendance growth increased rather than decreased as the semester progressed.

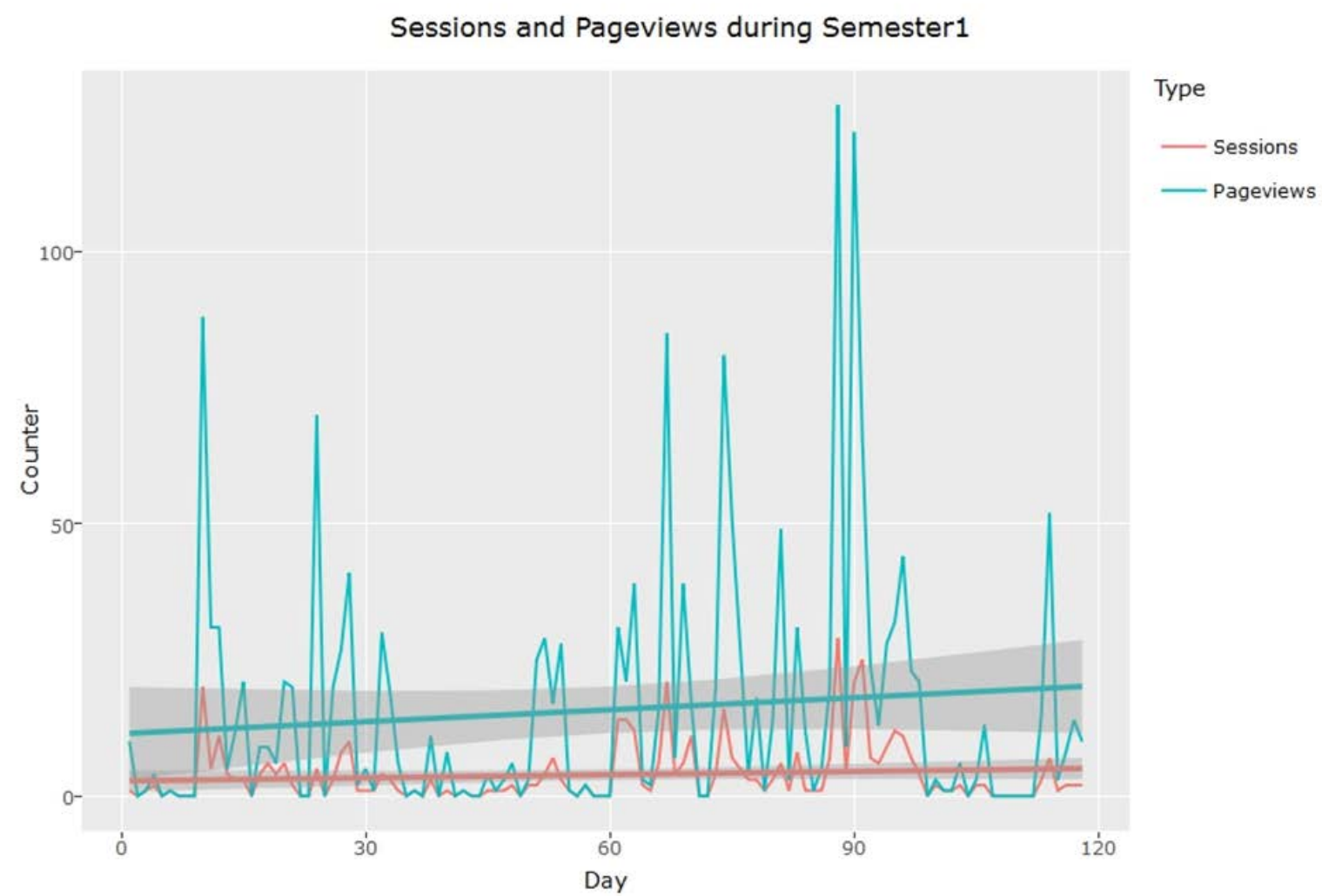

Figure 1: Counting sessions and page views during semester 1. Straight lines depict the linear model fitted to the data. 


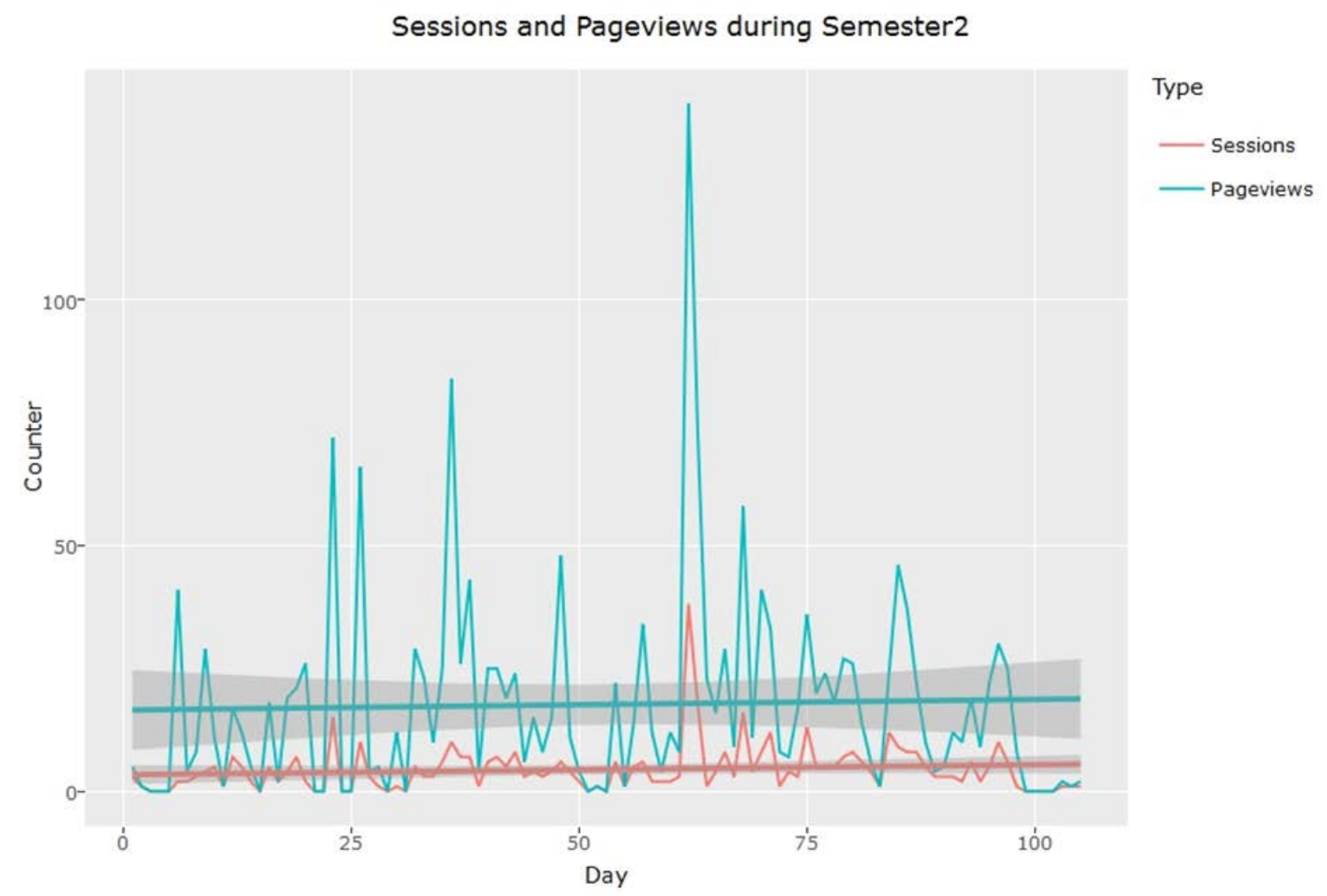

Figure 2: Counting sessions and page views during semester 2. Straight lines depict the linear model fitted to the data.

The OERs, educational components of the QL website, comprised mostly open-source videos, developed and shared voluntarily by mathematics teachers and academics from all over the world. Currently, the internet is a growing source of such OERs, in particularly in the field of science, technology, engineering and mathematics (Porcello and Hsi 2013). For our purposes, the resources were curated, taking into consideration the language, presentation quality, subject contents and relevance to the courses taken by the students, then they were packaged into learning objects for web deployment. Subsequently, the created LOs were embedded in a plexus-like structure with a prequel and sequel links. The prequel links led to the material necessary for understanding of the current learning object content and helped the students to acquire the missing prerequisite knowledge, since this facility is often necessary for the successful completion of the course (Diamond 2011). In contrast, the sequel links led to the LOs containing the next stepping stone in mathematical knowledge attainment.

During the design phase, the selection process applied to OERs was guided by a need for alignment of the LOs to the study objectives and learner outcomes in areas of calculus, mathematics for engineering, quantitative methods, statistics and linear algebra. Moreover, a digital roadmap, constructed on the base of a Google document, was developed as a functional 
mapping between the study guide chapters and corresponding LOs. Under those circumstances, the students were able to traverse the plexus according to the prerequisites and sequels set for each learning object.

The traditional face-to-face cohorts met for two hours, seven times during the semester, during which the instructors used the standard lecture techniques together with group-orientated work. These students did not belong to QL registered end-users, however, they were not precluded from using internet resources on their own initiative either.

The online student cohorts could access the website at any time and they had been encouraged to do this through e-mail messages and announcements. Also, induction meetings were organised for them, where basic functionalities of the portal were explained by the instructors. Additionally, the assignment and exam pack, made of thematically arranged LOs, pertinent to the knowledge necessary for succeeding in the formative and summative assessments, were provided for selected modules. Finally, the blended student cohorts were both the end-users of the QL portal and attendees of F2F sessions.

The participants in the project comprised the students that have enrolled for first-year mathematics modules. However, the sample was of a convenience type, as the students were recruited from the self-selected volunteers participating in the additional support programme. Only the students that had necessary means, in particular internet access and some expertise in navigating the web, were able to benefit. For the participants that stay in a proximity of the regional office, the computer facilities and technical assistance were provided. The validity of the measuring instruments, in our case the academic assignment and exam marks, was guaranteed by the institutional student evaluation processes.

The data sources pertaining to the student information consisted of:

- $\quad$ website registration files and attendance registers

- $\quad$ assignments and exam marks

The site administrators collected the registration information from the website's authorisation database. Since the students attending F2F tutorials filled in the attendance registers, these, in turn, were scanned and digitised. Next, the academic results were collected from the institutional database. Afterwards, all the data was cleaned and uploaded to the warehouse, built on top of Microsoft SQL Server technology.

The R statistical package was selected as the most convenient tool for running detailed queries, providing insightful analysis and producing meaningful textual and graphical output. By virtue of the openness and modular structure of the $\mathrm{R}$ statistical package, especially the 
database connectivity interfaces, the entire information system was set up in a single continuous environment. Moreover, the size of the differences between the groups was determined using the Wilcoxon rank sum test with continuity correction. Finally, the use of this nonparametric method was dictated by the small sample sizes, as will be revealed in the following section.

Access to the students' data was provided by Research Permission Subcommittee (RPSC), the permission to use it was obtained from Professional and Administrative Research Committee (PARC), both subdivisions of Unisa Senate Research and Innovation and Higher Degrees Committee (SRIHDC).

\section{RESULTS}

During the acquisition of data in relation to the exam marks, we decided to incorporate only the students whose final results outcome belonged to the categories: 'Failed', 'Passed' or 'Pass with Distinction'. In this way, those candidates who were absent from examination, for various reasons (e.g. financial or no-show), were eliminated from further analysis. Hence, the student sample - with the final results in the first semester of 2015 - consisted of 170 learners writing exams in five, semester long modules, and they were provided with various additional learning support interventions. The modules were:

- $\quad$ MAT1503 - Linear Algebra, a standard introductory course for students of science: systems of linear equations, determinants, vectors, vector spaces and matrices.

- $\quad$ MAT1581 - Engineering Mathematics with the focus on mining engineers: various types of equations, trigonometry, geometry, complex numbers, limits, differentiation and integration.

- MAT1512 - Calculus, an introductory course for science students: limits, differentiation, integration, differential equations and partial derivatives.

- QMI1500 - Elementary Quantitative Methods teaching the basics of numerical manipulation, modelling, financial mathematics, indices and descriptive statistics.

- $\quad$ DSC1520 - Quantitative Modelling with the focus on students of economics: linear and nonlinear functions, linear algebra and beginning calculus.

A detailed headcount of the student participation is provided in Table 1. 
Table 1: Exam writing - student distribution for semester 1 of 2015

\begin{tabular}{|l|l|l|l|l|}
\hline Module & Blended & F2F & Online & Total \\
\hline DSC1520 & 24 & 15 & 6 & 45 \\
\hline MAT1503 & 2 & 5 & 6 & 13 \\
\hline MAT1512 & 4 & 5 & 6 & 15 \\
\hline MAT1581 & 3 & 2 & 11 & 16 \\
\hline QMI1500 & 27 & 43 & 11 & 81 \\
\hline Total & $\mathbf{6 0}$ & $\mathbf{7 0}$ & $\mathbf{4 0}$ & $\mathbf{1 7 0}$ \\
\hline
\end{tabular}

The student sample, with exam results in the second semester of 2015, contained 220 students. Despite the seasonal effects (traditionally, a smaller number of students register during the winter as compared with the summer semester), we have increased the size of student sample, as we introduced a more aggressive and fruitful recruitment strategy. Moreover, we added one new module to the domain, STA1510 - Basic Statistics, an introductory course in statistics teaching about descriptions of data, measures of central location, probability distributions, confidence levels and hypothesis testing. The detailed headcount of the student participation during the second semester can be found in Table 2 .

Table 2: Exam writing - student distribution for semester 2 of 2015

\begin{tabular}{|l|l|l|l|l|}
\hline Module & Blended & F2F & Online & Total \\
\hline DSC1520 & 2 & 10 & 8 & 20 \\
\hline MAT1503 & 8 & 7 & 21 & 36 \\
\hline MAT1512 & 12 & 8 & 17 & 37 \\
\hline MAT1581 & 8 & 7 & 11 & 26 \\
\hline QMI1500 & 28 & 49 & 11 & 88 \\
\hline STA1510 & 2 & 8 & 3 & 13 \\
\hline Total & $\mathbf{6 0}$ & $\mathbf{8 9}$ & $\mathbf{7 1}$ & $\mathbf{2 2 0}$ \\
\hline
\end{tabular}

For the assignment data analysis, we lifted the restrictions applied to the final exam data regarding absent students. Consequently, the students, who did not write exams, can also be found in the assignment sample. For the first semester of 2015, the sample contained 175 students, as presented in Table 3. 
Table 3: 'Assignment' - student distribution for semester 1 of 2015

\begin{tabular}{|l|l|l|l|l|}
\hline Module & Blended & F2F & Online & Total \\
\hline DSC1520 & 23 & 14 & 7 & 44 \\
\hline MAT1503 & 2 & 8 & 10 & 20 \\
\hline MAT1512 & 4 & 5 & 8 & 17 \\
\hline MAT1581 & 4 & 3 & 12 & 19 \\
\hline QMI1500 & 25 & 38 & 12 & 75 \\
\hline Total & $\mathbf{5 8}$ & $\mathbf{6 8}$ & $\mathbf{4 9}$ & $\mathbf{1 7 5}$ \\
\hline
\end{tabular}

The second semester sample of 2015 contained 248 students and one additional module. The distribution can be found in Table 4.

Table 4: 'Assignment' - student distribution for semester 2 of 2015

\begin{tabular}{|l|l|l|l|l|}
\hline Module & Blended & F2F & Online & Total \\
\hline DSC1520 & 3 & 11 & 11 & 25 \\
\hline MAT1503 & 9 & 9 & 25 & 43 \\
\hline MAT1512 & 15 & 8 & 17 & 40 \\
\hline MAT1581 & 11 & 8 & 13 & 32 \\
\hline QMI1500 & 30 & 50 & 14 & 94 \\
\hline STA1510 & 2 & 8 & 4 & 14 \\
\hline Total & $\mathbf{7 0}$ & $\mathbf{9 4}$ & $\mathbf{8 4}$ & $\mathbf{2 4 8}$ \\
\hline
\end{tabular}

After the conclusion of the academic year, we compared the averages of assignment and exam results for all the modules and modal groups against the total student population for these modules. The research question we have been answering here could be formulated as follows: 'Did the students studying a module and having additional support, perform better than all the students in this module?' The results of the statistical analysis represented by p-values are summarised in Table 5. 
Table 5: P-values originated from the Wilcoxon rank sum test across various modules and learning modes. Underlined values are statistically significant on level 0.05

\begin{tabular}{|c|c|c|c|c|c|c|c|}
\hline \multirow{2}{*}{ Module } & & \multicolumn{3}{|c|}{ Semester 1} & \multicolumn{3}{|c|}{ Semester 2} \\
\hline & & Blended & F2F & Online & Blended & F2F & Online \\
\hline \multirow[t]{4}{*}{ DSC1520 } & Exam & 0.22500 & 0.87490 & 0.45900 & 0.17440 & 0.14080 & 0.83340 \\
\hline & Asg 1 & $\underline{0.00747}$ & $\underline{0.03765}$ & 0.09376 & 0.19740 & $\underline{0.00025}$ & 0.25280 \\
\hline & Asg 2 & $\underline{0.04693}$ & 0.06643 & 0.72860 & 0.49490 & 0.37540 & 0.49950 \\
\hline & Asg 3 & $\underline{0.00002}$ & $\underline{0.00002}$ & 0.19630 & 0.40450 & $\underline{0.00044}$ & $\underline{0.00325}$ \\
\hline \multirow[t]{4}{*}{ MAT1503 } & Exam & 0.17080 & 0.54580 & 0.45010 & 0.08585 & 0.35670 & $\underline{0.00427}$ \\
\hline & Asg 1 & 0.40200 & 0.09099 & $\underline{0.00918}$ & $\underline{0.00004}$ & $\underline{0.00810}$ & $\underline{0.00048}$ \\
\hline & Asg 2 & 0.42110 & 0.25470 & $\underline{0.00105}$ & 0.51940 & 0.16230 & 0.06347 \\
\hline & Asg 3 & 0.38410 & 0.25130 & 0.06286 & $\underline{0.01775}$ & 0.06701 & $\underline{0.03029}$ \\
\hline \multirow[t]{3}{*}{ MAT1512 } & Exam & 0.27010 & 0.86370 & 0.17070 & 0.11420 & 0.68820 & $\underline{0.01172}$ \\
\hline & Asg 1 & 0.83300 & 0.68710 & $\underline{0.04972}$ & $\underline{0.00340}$ & $\underline{0.04074}$ & 0.07167 \\
\hline & Asg 2 & 0.81160 & 0.35700 & 0.43030 & 0.06343 & 0.15200 & 0.18930 \\
\hline \multirow[t]{4}{*}{ MAT1581 } & Exam & 0.06448 & $\underline{0.03134}$ & 0.94320 & 0.51700 & $\underline{0.02407}$ & 0.27620 \\
\hline & Asg 1 & 0.29970 & 0.06716 & 0.68510 & $\underline{0.03282}$ & 0.88310 & 0.06007 \\
\hline & Asg 2 & 0.17030 & 0.59530 & 0.08238 & 0.74160 & 0.06432 & 0.18430 \\
\hline & Asg 3 & 0.07952 & 0.19660 & 0.72820 & 0.14340 & $\underline{0.03504}$ & $\underline{0.01676}$ \\
\hline \multirow[t]{4}{*}{ QMI1500 } & Exam & 0.28600 & 0.69780 & 0.87710 & 0.00213 & 0.72220 & 0.44910 \\
\hline & Asg 1 & $\underline{0.00001}$ & $\underline{0.00040}$ & 0.89230 & $\underline{0.00000}$ & $\underline{0.00593}$ & 0.51530 \\
\hline & Asg 2 & $\underline{0.00004}$ & $\underline{0.01062}$ & 0.55440 & $\underline{0.00001}$ & $\underline{0.00149}$ & 0.76080 \\
\hline & Asg 3 & $\underline{0.00943}$ & $\underline{0.04150}$ & 0.54400 & $\underline{0.00028}$ & 0.09111 & 0.18630 \\
\hline \multirow[t]{3}{*}{ STA1510 } & Exam & No Data & No Data & No Data & 0.26780 & 0.92190 & 0.96670 \\
\hline & Asg 1 & No Data & No Data & No Data & 0.11930 & 0.35760 & 0.71250 \\
\hline & Asg 2 & No Data & No Data & No Data & 0.03553 & 0.26160 & 0.82730 \\
\hline
\end{tabular}

Another question, pertaining to the differences between particular learning modes, could be 
designed in a following manner: 'Did the online group perform significantly better than other groups?' We have limited our investigation here to the exam results only, as this method of summative assessment carries decisive weight on the students' progress evaluation. The outcomes of the statistical analysis are presented in Table 6.

Table 6: Comparison within learning modes. The 'Avg' column presents the averages of exam marks for each learning mode and the total student population. P-values arise from the comparison of online with blended and F2F modes. Underlined values are statistically significant on level 0.05 .

\begin{tabular}{|c|c|c|c|c|c|c|}
\hline \multirow{3}{*}{ Module } & \multicolumn{6}{|c|}{ Semester 1} \\
\hline & Blended & & F2F & & Online & All \\
\hline & Avg & P-Value & Avg & P-Value & Avg & Avg \\
\hline DSC1520 & 51.67 & 0.5823 & 42.22 & 0.2662 & 48.89 & 48.66 \\
\hline MAT1503 & 57.00 & 0.6786 & 40.60 & 0.3961 & 43.17 & 42.85 \\
\hline MAT1512 & 36.75 & 0.2250 & 23.00 & 0.1645 & 47.67 & 34.65 \\
\hline MAT1581 & 60.42 & 0.9693 & 61.88 & 0.9885 & 26.48 & 36.48 \\
\hline QMI1500 & 47.70 & 0.9431 & 44.21 & 0.7809 & 38.87 & 45.33 \\
\hline \multirow{3}{*}{ Module } & \multicolumn{6}{|c|}{ Semester 2} \\
\hline & Blended & & F2F & & Online & All \\
\hline & Avg & P-Value & Avg & P-Value & Avg & Avg \\
\hline DSC1520 & 55.00 & 0.9425 & 53.33 & 0.9404 & 39.16 & 46.04 \\
\hline MAT1503 & 37.62 & 0.4131 & 31.71 & 0.2450 & 39.10 & 27.90 \\
\hline MAT1512 & 50.75 & 0.2256 & 36.25 & $\underline{0.0455}$ & 57.35 & 41.88 \\
\hline MAT1581 & 36.09 & 0.2813 & 54.11 & 0.7931 & 41.70 & 37.22 \\
\hline QMI1500 & 48.69 & 0.9394 & 38.03 & 0.3401 & 40.30 & 39.94 \\
\hline STA1510 & 50.00 & 0.9809 & 32.00 & 0.8747 & 25.33 & 41.05 \\
\hline
\end{tabular}

\section{DISCUSSION}

The detailed review of the results in Table 5 prompted us to perform some generalisations and we have decided to categorise the samples into three groups that exhibit similar behaviour patterns. We did not use the actual averages in this analysis, as some of the samples were substantially small and the considerable gain or loss with respect to the comparative average mark is considerably muted by the sample size effect. The analysed data illustrate following trends and behaviours: 
- $\quad$ Group 1 - consisting of DSC1520 and QMI1500 students.

This group benefited from blended and F2F sessions rather than online access during the assignments writing and submission. However, the success in assignment performance did not translate into superior exam marks.

- $\quad$ Group 2 - consisting of MAT1581 students.

Here the significant benefit was drawn from F2F sessions as the exam results were significantly better than an average and the online students did not perform better than others.

- $\quad$ Group 3 - consisting of MAT1503 and MAT1512 students.

The online students from this group attained final examination results better than the general population of the students in above modules.

There is a substantial correlation between the above groupings and the academic areas the investigated modules belong to. Group 1 included modules that students are required to pass in the College of Economic and Management Sciences. The Group 2 module is delivered by the College of Science, Engineering and Technology, but it is a specialised subject geared towards engineering students. Finally, Group 3 modules is also provided by the College of Science, Engineering and Technology, however, the target here is the science students rather than students in engineering. We have decided not to group the STA1510 module, as the results of the analysis did not exhibit anything inconsistent with the null hypothesis.

The results in Table 6 exhibit less meaningful information, as the P-values are not in the statistical significance range, with only one exclusion, namely MAT1512 during the second semester. We provided averages here, however, because of the small group sizes, one should not regard them as decisively meaningful in all cases. MAT1512 had 12 blended students, 8 F2F students and 17 online students and the average of the online students (39.10) significantly surpassed the averages for other modes (37.62 for blended and 31.71 for F2F cohorts) during the same period. The box plot, comparing average performance for module MAT1512 across various modes, is displayed in figure 3.

\section{SUMMARY}

The need for learning support services is highly appreciated by contact and ODL institutions. The type of the support, however, should vary, as many ODL students in South Africa often do not have time or resources to participate in extensive support programmes. Instructional support 


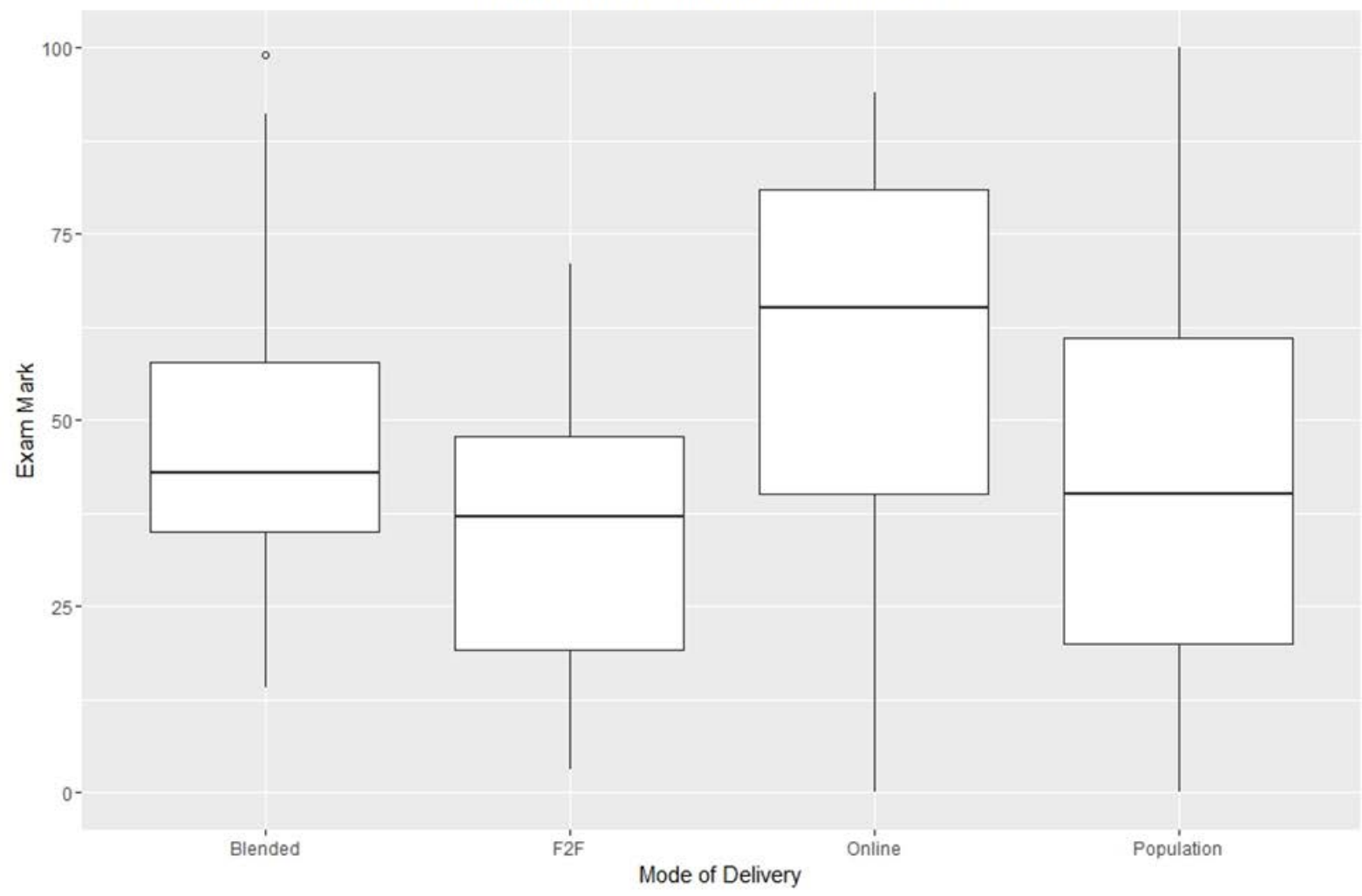

Figure 3: Box plot comparing academic performance for different modes of additional support delivery of the MAT1512 module in semester 2.

and face-to-face sessions can be helpful to only those students, who live in a direct proximity of the university or regional offices. This is why it is important to look and create support modes that can be utilised without spatial or temporal restraints. Obviously, such support has to be previously proven to be effective in the knowledge delivery. As we are undergoing the technological and informational revolution, a quite obvious direction to look at is the internet technology and resources shared online. Following this trend, we have created an online portal, as an alternative to F2F session, source of additional learning support and performed an investigation to ascertain whether the students, who use the online facility, benefited by achieving elevated academic outcomes.

The results of this study indicate that there exists a complex relationship between the mode of learning support and students' academic success. Nevertheless, we could analyse it in terms of the learning abstraction levels, as suggested by Lu and Lemonde (2013) and Ross and Bell (2007). Thus, in our categorisation, Group 1, comprising business and economics students, would be assigned the lowest learning abstraction level, whereas Group 3, comprising science students, would have the highest learning abstraction level. Firstly, we have found that the students in Group 1 were benefiting from F2F sessions and the blended mode of learning support during the academic year when the assignments were written. Attainment of high 
assignment marks could be explained by the diligent and helpful attitude of tutors. However, their participation in the programme did not induce this cohort to achieve high exam results and, in particular, the online support did not provide any meaningful assistance to this cohort. Secondly, Group 2, comprising students of engineering, benefited mostly via F2F sessions, as this mode has shown exam results better than the general student population in MAT1581 module. Finally, Group 3, decisively applied online facilities to their advantage, as the students performed better during the second semester exam session. This result was absent during the first semester; however, one has to notice that QL was under development during this time and the bulk of the OERs had not been fully curated and embedded earlier than in the middle of 2015.

Since the sample in the quasi-experiment was of a convenience type, one cannot extend these results generally, as self-selection of the students introduces the bias by assigning nonrandom characteristics to cohorts using particular support modes. An obvious way to alleviate this undesirable tendency is to create a true random sample involving a much larger student group and splitting it randomly into the control and test groups. Another is to conduct a qualitative post-experimental research in order to find confounding variables and the rates of the true participation in the support modes. Finally, this study could be developed further by improving or varying the online intervention and exploring whether additional or different scaffolding would affect the academic achievement of the participating students in a different way.

\section{REFERENCES}

Allen, I. E., J. Seaman and R. Garret. 2007. Blending in: The extent and promise of blended education in the United States. Sloan Consortium. MA: Newburyport.

Allen, I. E. and J. Seaman. 2011. Going the distance: Online education in the United States, 2011. Sloan Consortium. MA: Newburyport.

Ashby, J., W. A. Sadera and S. W. McNary. 2011. Comparing student success between developmental math courses offered online, blended, and face-to-face. Journal of Interactive Online Learning 10(3): 128-140.

Baggaley, J. 2012. Global education: From Genghis Khan to Facebook. Routledge.

Barritt, C., D. Lewis and W. Wieseler. 1999. Cisco Systems Reusable Information Object Strategy. RIO Strategy v3.0: 23-43.

Bojuwoye, O., M. Moletsane, S. Stofile, N. Moolla and F. Sylvester. 2014. Learners' experiences of learning support in selected Western Cape schools. South African Journal of Education 34(1): 115.

Brown, M., H. Hughes, M. Keppell, N. Hard and L. Smith. 2013. In their own words: student stories of seeking learning support. Open Praxis 5(4): 345-354.

Browne, T., R. Holding, A. Howell and S. Rodway-Dyer. 2010. The challenges of OER to Academic Practice. Journal of Interactive Media in Education 1(3): 1-15 
Browne, T. and M. Newcombe. 2009. Open educational resources: a new creative space. Proceeding Ascilite Auckland 2009: 1170-1179.

Butcher, N. 2015. A basic guide to open educational resources (OER). Commonwealth of Learning, Vancouver and UNESCO.

Chawla, S., N. Gupta and R. K. Singla. 2012. LOQES: Model for evaluation of learning object. International Journal of Advanced Computer Science and Applications 3(7): 73-79.

Clow, D. 2013. MOOCs and the funnel of participation. In Proceedings of the Third International Conference on Learning Analytics and Knowledge, ed. D. Suthers, K. Verbert, E. Duval and X. Ochoa, 185-189. ACM.

Cuseo, J. 2007. Defining student success: First critical first step in promoting it. E-Source for College Transitions 4(5): 2-5

Declaration, Cape Town Open Education. 2007. Cape Town Open Education Declaration: Unlocking the promise of open educational resources. http://www.capetowndeclaration.org/read-thedeclaration (accessed 7 February 2017).

Diamond, R. M. 2011. Designing and assessing courses and curricula: A practical guide. John Wiley \& Sons.

Dias, O., A. W. Cunningham and L. Porte. 2016. Supplemental instruction for developmental mathematics: Two-year summary. MathAMATYC Educator 7(2): 4-9.

Hilton J. L., D. Gaudet, P. Clark, J. Robinson and D. Wiley. 2013. The adoption of open educational resources by one community college math department. The International Review of Research in Open and Distributed Learning 14(4): 37-50.

Holden, J. and P. J. L. Westfall. 2010. An instructional media selection guide for distance learning Implications for blended learning. United States Distance Learning Association (USDLA). https://www.usdla.org/wp-content/uploads/2015/05/AIMSGDL_2nd_Ed_styled_010311.pdf (accessed 12 February 2017).

Jaafar, R., A. Toce and B. A. Polnariev. 2016. A multidimensional approach to overcoming challenges in leading community college math tutoring success. Community College Journal of Research and Practice 40(6): 534-549.

Jarvis, P. 2006. Transforming learners through open and distance learning. The Theory and Practice of Teaching: 224. Routledge.

Learning Technology Standards Committee. 2002. IEEE Draft Standard for Learning Object Metadata. IEEE Standard 1484: 12.

Lu, F. and M. Lemonde. 2013. A comparison of online versus face-to-face teaching delivery in statistics instruction for undergraduate health science students. Advances in Health Sciences Education 18(5): 963-973.

Malm, J., L. Bryngfors and L-L. Morner. 2011. Supplemental instruction: Whom does it serve? International Journal of Teaching and Learning in Higher Education 23(3): 282-291.

Moore, J. L., C. Dickson-Dean and K. Galyen. 2011. e-Learning, online learning, and distance learning environments: Are they the same? The Internet and Higher Education 14(2): 129-135.

Oyedemi, T. D. 2012. Digital inequalities and implications for social inequalities: A study of internet penetration amongst university students in South Africa. Telematics and Informatics 29(3): 302313.

Phelps, J. M. and R. Evans. 2006. Supplemental instruction in developmental mathematics. The Community College Enterprise 12(1): 21.

Polsani, P. R. 2006. Use and abuse of reusable learning objects. Journal of Digital information 3(4): 110.

Porcello, D. and S. Hsi. 2013. Crowdsourcing and curating online education resources. Science 341(6143): 240-241.

Raghuveer, V. R. and B. K. Tripathy. 2012. An object oriented approach to improve the precision of 
learning object retrieval in a self-learning environment. Interdisciplinary Journal of E-Learning and Learning Objects 8(1): 193-214.

Raward, R. 2001. Academic library website design principles: Development of a checklist. Australian Academic \& Research Libraries 32(2): 123-136.

Ross, T. K. and P. D. Bell. 2007. No significant difference only on the surface. International Journal of Instructional Technology and Distance Learning 4(7): 3-13.

Sapire, I. and Y. Reed. 2011. Collaborative design and use of open educational resources: A case study of a mathematics teacher education project in South Africa. Distance Education 32(2): 195-211.

Sharma, A., B. Bryant and M. Murphy. 2013. Assessing face to face and online course delivery using student learning outcomes. In Proceedings of the Information Systems Educators Conference ISSN 2167: 1435.

Smith, N. V. 2013. Face-to-face vs. blended learning: Effects on secondary students 'perceptions and performance'. Procedia-Social and Behavioral Sciences 89: 79-83.

Subotzky, G. and P. Prinsloo. 2011. Turning the tide: A socio-critical model and framework for improving student success in open distance learning at the University of South Africa. Distance Education 32(2): 177-193.

Tolley, H. and H. MacKenzie. 2015. Senior management perspectives on mathematics and statistics support in higher education. Sigma, Loughborough University. http://www. sigma-network.ac. uk/wp-content/uploads/2015/05/sectorneeds-analysis-report.pdf. (accessed May 2015)

Tyma, P. 1998. Why are we using Java again? Communications of the ACM 41(6): 38-42.

Wiley, D., T. J. Bliss and M. McEwen. 2014. Open educational resources: A review of the literature. In Handbook of research on educational communications and technology, ed. M. Spector, M. D. Merrill, J. Elen and M. J. Bishop, 781-789. Springer New York. 